\section{EMBRYARIDDLE}

Aeronautical University

SCHOLARLY COMMONS
Journal of Aviation/Aerospace

Education \& Research

Volume 19

Number 1 JAAER Fall 2009

Article 6

Fall 2009

\title{
Small General Aviation Airport Emergency Preparedness and the Perceived Risks of Very Light Jet Operations
}

Stanley L. Harriman

Richard O. Fanjoy

Donald A. Petrin

Follow this and additional works at: https://commons.erau.edu/jaaer

\section{Scholarly Commons Citation}

Harriman, S. L., Fanjoy, R. O., \& Petrin, D. A. (2009). Small General Aviation Airport Emergency Preparedness and the Perceived Risks of Very Light Jet Operations. Journal of Aviation/Aerospace Education \& Research, 19(1). https://doi.org/10.15394/jaaer.2009.1382

This Article is brought to you for free and open access by the Journals at Scholarly Commons. It has been accepted for inclusion in Journal of Aviation/Aerospace Education \& Research by an authorized administrator of Scholarly Commons. For more information, please contact commons@erau.edu. 


\title{
SMALL GENERAL AVIATION AIRPORT EMERGENCY PREPAREDNESS AND THE PERCEIVED RISKS OF VERY LIGHT JET OPERATIONS
}

\author{
Stanley L. Harriman, Richard O. Fanjoy, and Donald A. Petrin
}

\begin{abstract}
Advances in aircraft design have facilitated to the development of relatively low cost, high performance, light weight jet aircraft known as very light jets (VLJs). The Federal Aviation Administration's prediction of 4,500 VLJs flying by 2016 suggests that this concept may become a major contributing factor for gridlock in the National Airspace System (NAS) (Robinson and Planzer, 2005). With this added burden, the need for effective emergency response at general aviation airports will continue to increase. This study investigated the level of emergency response preparedness of small general aviation airports in the state of Indiana that may service very light jets and measured attitudes of airport managers regarding the perceived risks of VLJ operations. Findings suggest that airport managers believe smaller airports are prepared to handle the growth in VLJ traffic and generally are not concerned with increasing the level of emergency response planning. This study concludes with recommendations for emergency enhancements at smaller airports not certified under Part 139.
\end{abstract}

\section{Introduction}

A major concern affecting the continuing viability of general and business aviation involves the development of relatively low cost, high performance, light weight jet aircraft known as very light jets (VLJs), and their impact on airport and airspace traffic that approaches systems capacity. The Federal Aviation Administration's prediction of 4,500 very light jets flying by 2016 suggests that this rate of growth may be a major factor for gridlock in the National Airspace System (Robinson and Planzer, 2005).

Very light jets are small, turbofan-powered aircraft that weigh up to 10,000 pounds, can operate from runways as short as 3,000 feet, reach altitudes of between 19,000 and 41,000 feet, and travel distances of around 1,300 nautical miles at speeds between 350 and 380 knots. Priced between $\$ 1.3$ to $\$ 3$ million, the cost of most VLJs is significantly less than current light business jets. As a result, many emerging air taxi companies are planning on using VLJ's to support point-to-point air charter services. In a 2002 report, the Transportation Research Board of the National Academies concluded that the VLJ-based air taxi concept was problematic in several ways. Issues to be resolved include public concern about safety, environmental consequences (aircraft noise), airport security, and passenger service standards (Wall, 2005). With the expectation of rising general aviation airport use, particularly due to the expansion of VLJs, the need for fire fighting and emergency services at those airports will also become more prominent.

Emergency planning and associated resources are aspects of complex decision-making systems that airport managers apply in a wide variety of ways. Airport agencies that are influenced by emergency planning include aircraft maintenance, flight operations, ground handling, fueling services, airside services, and air traffic control. The lack of a standardized system to integrate the safety practices of different agencies in and around the airport has an adverse effect on overall safety. Even when common safety procedures are employed by the same organization, they can be subject to different management protocols, different training quality or standards, and reflect a varied safety culture (ETSC, 1999).

\section{Secondary Airports outside the}

Traditional Hub and Spoke Model

Nearly 98 percent of the nation's population lives near a community airport, out of that figure, only 28 percent live near a hub airport (Espinoza, 2006). Kiplinger (2006) 
declares, "While America's 31 major hub airports choke on soaring passenger volume, a few thousand other airports in small cities, and on the fringes of big ones, have plenty of capacity." The available capacity, defined as the "average maximum sustainable throughput", at surrounding airports is twice the existing capacity at core airports (para. 3 ).

Since VLJs are specifically designed to operate from runways as short as 3,000 feet. This makes them ideal for providing point-to-point services to more than 5,000 U.S. airports serving small to medium-sized aircraft (Boeing, 2005). Through its operations at smaller, underserved airports, the VLJ can increase overall airport usage and capacity in the National Airspace System.

Air taxi operators embraced the VLJ concept as an opportunity to provide a partial substitute for regional aviation market services not available from the present airline hub-and-spoke transportation networks, which traditionally connect flights to a larger airport before reaching the final destination (Viken, 2006). The expected increase in personal jet activity has led to high expectations by many local community leaders, who recognize that adequate airport facilities are a catalyst for economic development. Robinson and Planzer (2005) suggest that smaller rural airports, which VLJs are likely to utilize, may not have the necessary services and emergency response capabilities to accommodate increased air and ground traffic. Any action to provide services for very light jets will increase connectivity of the general public to smaller community markets (Hughes, 2005).

Emergency Rescue and Response Training

In the United States, the FAA has the primary responsibility for developing standards, criteria, and guidelines on how airport rescue and firefighting (ARFF) services shall be performed at Part 139 certified airports. At airports not certified under Part 139, the training of aviation firefighters is largely the responsibility of individual airport administrators. Accordingly, there is considerable variation between such airports in the frequency and quality of training. The complexity of the aviation environment, current firefighting equipment, and available extinguishing agents suggests that a proficient level of performance will only be achieved through thorough training of responsible personnel (Wright, 2001).

Findings from a study of jet aircraft accidents by the FAA and the Airport Improvement Program (AIP) suggest that emergency responders effectively controlled accidents that involved external fuel fires. However, secondary fires within the aircraft fuselage were difficult to control with existing equipment and procedures (Wright, 2001). Another discovery from the study is that firefighters, in general, do not have sufficient specialized equipment to gain rapid aircraft entrance and that they receive minimal training to perform this task. It is essential for local fire and rescue departments to be prepared for aviation fire fighting, aircraft design (including different compartments and materials), location of fuel tanks and exits, and exterior openings for forcible entry into the fuselage of conventional jet aircraft (Kuepper, 2000).

One of the key factors in measuring the effectiveness of an airport's emergency response is the amount of time that elapses from recognition of an emergency situation to prompt notification of emergency service providers. For an emergency response to be effective, airport personnel and administrators must have a detailed plan in place that pre-assigns roles and responsibilities in the event of an emergency. An effective emergency plan must consider such factors as terrain, weather, road networks, population, airport infrastructure, proximity to other potential dangers, training level, equipment possessed by local responders, and availability of resources from neighboring communities when planning for their actions. These basic requirements should be considered in the airport's standard operating procedures (SOPs) and response plans to prevent further delay or confusion during a rescue operation. Since aviation accidents frequently occur near, rather than at airports, integrating the activities of local and airport emergency services is another major planning factor (ETSC, 1999). Accountability issues will also need to be determined for each employee to prevent delay in completion of assigned actions during emergency situations. A safety program that identifies hazards but does not address pertinent processes and conditions will not be an effective tool for educating emergency personnel and reducing incidents (Spillane, 2004).

In addition to onsite emergency response personnel, support is needed from local fire, EMS, and other emergency departments for water supply as well as personnel and equipment for rescue operations, triage, and transportation of injured victims to appropriate hospitals. Also, an ongoing source of trained responders is needed from local communities to replace those who move away. To provide these resources, there should be an ongoing recruitment methodology to enlist new community emergency responders for a variety of positions (Kuepper, 2000).

\section{Airport Geographical Limitations and Accessibility}

The geographical characteristics of the area immediately surrounding the airport can significantly affect response capabilities. Rural routes are often constructed over a period of years and as a result, may have inconsistent design features. Many rural roads have been built with narrow lanes, limited shoulders, excessive curves, and steep slopes alongside roadways making it difficult to quickly reposition large emergency equipment during an aircraft 
accident or incident (FHWA, 1999). Access may be further limited by poorly surfaced roads, minimal road infrastructure, wooded areas, and farmland with ditches and fences. For airports near these geographical features, emergency response services may be restricted due to an inability to expeditiously access off-airport accident sites.

\section{Methodology}

The purpose of this study was to assess emergency response plans and resources at small general aviation airports not certified under Part-139 and have the necessary attributes for very light jet operations. In order to satisfy the scope of the study, the researcher's objectives were to: 1) compile a list of Indiana's general aviation airports which were not Part-139 certified (Part-139 certification mandates a standardized level of training, manpower, and resources); 2) assess the extent of current emergency operating procedures (EOPs) and resources at the airports meeting the sample criteria; and 3) determine airport managers' attitudes regarding emergency response training.

General aviation airports in Indiana were chosen as a representative sample for the study due to the smaller annual number of business jet operations, takeoffs and landings, when compared with more business intensive states such as California, New York, Illinois, and Florida (Hughes, 2005).

\section{Participants}

The researchers compiled a list of non-Part 139 certificated general aviation airports in the state of Indiana with at least 3,500-foot of runway (paved surfaces only), runway lighting, instrument approach procedures, and a fixed-based operator that provided jet aircraft services (Jet A fuel/nitrogen/oxygen) and passenger amenities. Airports having these criteria were identified from the 2007 Airport Directory online database maintained by the Aircraft Owners and Pilots Association (AOPA) and the FAA's Airport/Facility Directory. According to these sources, the state of Indiana has 41 public-use airports that meet the necessary infrastructure and services. The researchers then made initial contact with airport managers by telephone to establish rapport and request participation. Those who agreed to participate were ensured anonymity in the study and corresponding email addresses were collected. Forty airport managers agreed to participate, and one declined due to limited time availability. Through the course of the study, 31 airport managers completed and submitted the survey during the time allotted for data collection. Ongoing contact with participants and survey follow-up reminders where completed by e-mail.

\section{Survey Instrument}

Participants were asked to respond to a 22-item survey that contained questions regarding airport personnel qualifications, regional characteristics that may delay rescue efforts, level of manpower, available on-site resources, extent of airport personnel emergency training, and perceived risks of VLJ operations. Some items from the survey utilized a Likert-type scale and were designed to capture the attitudes and level of general agreement or disagreement regarding concern for: 1) improving current emergency response planning and preparedness; 2) conducting appropriate initial or recurrent emergency response training; and 3) upgrading the availability and quality of services and facilities to better accommodate the emerging VLJ technology. Each item in the survey had a follow-on open-ended question that allowed the airport managers to provide supplementary details which offered insight into their levels of concern. For example, if airport managers did not feel that VLJs would have a significant impact on their daily operations, they could list the reason(s) for having little or no incentive to improve emergency protocols. The questionnaire concluded with an open-ended inquiry seeking any additional general concerns, not addressed previously, regarding VLJ activity on or near the vicinity of their airports.

A total of 31 out of 40 airport managers completed the survey during the one-month period allotted for data collection, which yielded a 77.5 percent rate of response. The survey data was analyzed using the Statistical Analysis Software (SAS) program to provide descriptive statistical information. Frequencies, means, standard deviations, and confidence intervals were computed for the Likert-type questions that addressed airport managers' attitudes on the perceived risks of VLJ operations. The qualitative data collected from the open-ended responses were coded and analyzed using the constant comparative and cross-case analysis method to identify emerging categories and themes. This involved grouping common answers to identical questions that later gave the researcher perspective on central or underlying issues.

To evaluate survey responses, established airport emergency protocols were consulted, including:

- Airport Emergency Plan - FAA Advisory Circular 150/5200-31 A

- Guidance for Developing and Auditing a Formal Safety Management System - Civil Aviation Authority CAP 726

- Safety Management Systems - Transport Canada, TP14326 
- Airside Safety Management - Civil Aviation Authority CAP 642

- Standards and Safety Practices (SARPs) International Civil Aviation Organization Annex 14 , Section 9.2

- Guide for Airport/Community Emergency Planning - National Fire Protection Association, NFPA 424

- Guide for Aircraft Accident Response - National Fire Protection Association, NFPA 422

- Recommended Practice for the Recurring Proficiency Training of Airtcraft Rescue and FireFighting Services - National Fire Protection Association, NFPA 405

The protocols listed above provide insight to variance in standards between operating procedures and suggest processes suitable for small general aviation airports. This method supported the relevancy of the recommendations made by the researcher to satisfy the standards for airport safety needs.

\section{Findings}

\section{General Aviation Airport Operations}

Civilian aviation flights generally can be divided into two operational categories: commercial and noncommercial. Commercial flights transport individuals and goods to generate revenue; they include operations of major airlines, regional air carriers, and air taxis. Noncommercial flights, usually called general aviation, encompass a wide array of activities such as: emergency medical services, sightseeing, flight training, crop dusting, recreation, and personal or business use. General aviation aircraft range from small private airplanes and business jets to helicopters and gliders.

The data suggests that most general aviation airports in this study are accustomed to jet aircraft operations. Approximately 90 percent of the airports that responded are home bases for business jets. It is assumed that such airports have sufficient services and facilities to accommodate essential needs. Commercial operations in the form of regional airline services are held at 26 percent of the airports, while business or corporate flight activities occur at 58 percent of the airports. Since very light jets are not significantly different from conventional business jets in terms of servicing and operations, an airport that is equipped to manage larger business jets should, in theory, be able to meet the needs of very light jets.

\section{Geographical Data}

Most major airports are close to the large cities they serve, and are surrounded by municipal fire stations. By contrast, fire stations near many smaller community airports are located wherever building sites were available. As a result, fire equipment in surrounding or nearby communities is frequently located several miles from the airport, often at the expense of longer emergency response times. Survey results indicate that all reporting airports were located within ten miles of an emergency response facility. Perhaps as significant, ninety percent of the airports reported to be located within 10 miles of the nearest hospital. Although firefighting and medical facilities seemed to be relatively close to some airports, there is an additional factor affecting response times - accessibility.

To further highlight the importance of giving provision to access to potential accident sites, approximately 71 percent of the airports in this study reported accessibility limitations in the area immediately surrounding their airport property (Figure 1). These shortcomings included poorly surfaced roads, limited road infrastructure, wooded areas, and farmland with ditches and fences. For such airports, emergency response services might be restricted due to limited access to an off-airport accident site ( $\mathrm{Li}, 2007)$. 


\section{Number of Airports with Limitations}

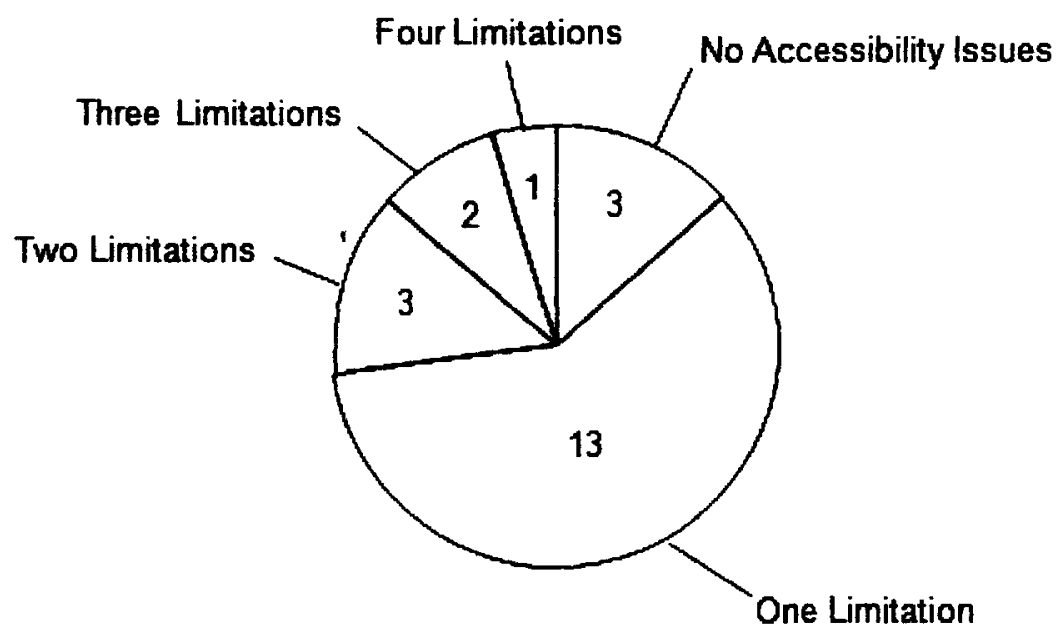

Figure 1. Sample airports with accessibility limitations for emergency vehicles.

\section{Airport Emergency Resources - Firefighting Equipment}

In order to successfully extinguish an aircraft fire, the most suitable type of extinguishing agent must be used. Selection of the proper agent has been made easier by the classification of fire types. Classes of fires involve materials with similar burning properties and require similar extinguishing agents (Flynn, 2007). Responses from the airports in this study show that 15 of the 31 airports, or 48 percent, only have one type of fire extinguishing agent available on-site. Two of those airports reported to only have water for that purpose. Such equipage does not address materials that require combinations of suitable extinguishing agents. A proactive approach by the airport administration must be adopted in order to have the necessary resources to address all possible fire types and hazards. Having more than one type of fire extinguishing agent on-site will increase the possibility of a successful and safe rescue operation. Twenty-one airports $(67.7 \%)$ reported to have a combination of fire extinguishing agents and forcible entry tools available on-site. However, the remaining ten airports did not have any forcible entry tools. Absence of extraction tools may make passenger extrication increasingly time consuming which lessens the survival chances for crash victims who initially sustained non-fatal injuries.

\section{Personnel Protection Gear/Equipment}

Since 79.9 percent of aircraft accidents happen during either departure or final approach, near or on the airport property, many first responders on the scene will be airport personnel or employees (Boeing, 1997). An essential resource for first responders is protective gear and equipment. Beyond the obvious danger of fire, unburned jet fuel is a carcinogen that can be absorbed through the skin; and prolonged inhalation of vapors can lead to development of chemical pneumonia. Another on-site hazard, the aircraft fuselage, may produce sharp edges that can easily tear through normal clothing. Surface control cables can be under extreme tension, and if cut, may separate with sufficient force to cause serious injury or death. Twentythree airports reported to not have any rescue protective gear for airport personnel. Airport managers need to consider the prediction that capacity enhancements and emerging technologies may aim towards utilizing the small-airport network and therefore, motive to re-assess their individual emergency response capabilities.

\section{Medical Supplies}

With regard to medical preparedness, 81 percent of the airports reported to have rudimentary first aid kits available on-site. Although this represented a high 
percentage of the population, the desired goal is 100 percent. Six airports reported no medical resources. Body splints and stretchers are a few basic medical resources needed to stabilize patients from any involuntary movement. After careful and timely passenger extrication, medical care should be given to optimize crash victims' survival and recovery. Breathing oxygen may also be needed after extraction to relieve oxygen deprivation and smoke inhalation (Osborn, 1997).

\section{Communication Equipment}

Communications equipment is a critical asset during emergency operations because following the recognition of an accident, the first-arriving unit needs to send an assessment report to other airport personnel and the appropriate emergency responders. This initial assessment report serves as an important role by providing the 911 dispatch center and all other rescuers with information needed to make the best decisions on how to respond and enables each rescue agency to formulate its own plans (Halpin, 2003). There were two airports in the sample that did not have communications resources such as: portable radios, cellular phones, megaphones, and caution signs or tapes. The remaining 29 airports reported to have at least one resource in this category. Although seven airports only utilize cellular phones to communicate with other personnel and community agencies, these devices can be quite effective for the communication process.

\section{Personnel Qualifications and Manpower}

When firefighters can reach the accident site in the first few minutes, for victims with non-fatal injuries, the survival rate is near 100 percent (CAAPS, 1999). Unfortunately, many airports do not have the capability to respond that quickly because they lack the necessary firefighting personnel and equipment. Additionally, personnel who are not trained to properly operate needed equipment may place the lives of passengers and firefighters at risk.

Five airports had at least one Airport Rescue and Fire Fighting (ARFF) individual on-site and eleven airport administrators reported the presence of ARFF trained firefighters in the local community. Many community airports are not federally required to have ARFF personnel onsite. As a result, there is a heavy reliance on the services provided by local emergency response agencies. However, local firefighter familiarity with the airport layout and operation, the different types of aircraft utilizing the airport, aircraft construction materials, and the potential hazards associated with a burning aircraft may be in question. The presence of ARFF trained personnel on-site or in the community will generally lead to proper coordination and planning of emergency response and rescue operations prior to and following an aircraft accident (CAAPS, 1999).

In addition to effective aircraft firefighting and rescue techniques, appropriate and timely medical support is also a determining factor for crash victims' survival. Correct medical applications can only be accomplished with knowledge attained from formal first aid, basic or advanced life support, or paramedic training programs. There were 20 of 31 airports that reported at least one employee trained in first aid. Thirteen airports reported at least one on-site employee trained in basic life support, advanced life support, or paramedic services. Seldom do aircraft survivors walk away from an accident without the need for medical attention prior to the arrival of emergency medical services (EMS) (Osborn, 1997). Training in first aid or basic life support will give airport personnel or first responders an advantage in assessing the seriousness of injuries and conducting proper medical aid.

Level of Emergency Training

Training is an on-going activity for all emergency response agencies. Not limited to the men and women that work the front line of an emergency event, training is also needed for many behind-the-scenes personnel who are vital to an effective emergency response. There were 16 of 31 airport managers who reported that the emergency response training they received was conducted under the authority of the local fire department. Six reported that airport management was the decision authority regarding the method and frequency of emergency training. Since airports in this study were not federally mandated to follow a certain training curriculum, there was considerable variance in the quality and frequency of training provided. It may be more effective for firefighters, volunteer firefighters, and airport personnel to attend training programs aimed towards Aircraft Rescue and Fire Fighting (ARFF) strategies.

Since there could be varied approaches to training methods, airport managers were asked to report on the frequency of emergency training and exercises conducted for airport employees and emergency response agencies within the local community. Approximately 60 percent of the airports surveyed do not participate in scheduled cooperative emergency response exercises. Two airports managers reported occasional participation in exercises, but commented to be "years overdue" for another emergency drill. Some local emergency managers and rescue providers felt that there is only a small likelihood of an airplane accident within their communities because they have not experienced one during their tenure. Since it is impossible to predict the location of future aircraft disasters, proper planning and preparation are essential.

Another key factor in the assessment of the response and preparedness of local emergency agencies is the measurement of response times. There are many reasons why rural emergency response times in rural areas are typically longer than in urban areas: increased travel distances; wider personnel distribution within the response areas; or additional time for volunteers traveling to emergency response facilities (Rawlinson, 2003). 
Approximately 68 percent of the surveyed airports have response times less than ten minutes, which is below the national average response times of emergency medical services (EMS) in rural areas (USDOT, 2004). However, this level of response may still be less than satisfactory since studies suggest that if the crash results in fire, an aircraft's aluminum skin may burn through in one minute, and in another two to three minutes the inside temperature reaches a lethal 1,800 degrees Fahrenheit.

Emergency Response - Community Preparedness

If emergency resources on the airport premises are limited and airport personnel rely heavily on local emergency services to effectively handle an aircraft accident, assembling a formal agreement and airport emergency plan with community agencies should be seen as a cost effective way to coordinate known resources and increase preparedness. Planning for an effective disaster response requires superb coordination between emergency service agencies and should address accessibility issues for potential accident sites. Roles and responsibilities of those responding must be clearly defined and an inventory of needed physical resources developed. Emergency response planning must ensure that a community has the necessary personnel, equipment, and procedures to respond effectively to aviation emergencies and disasters of varying scale (Comfort, 2004). Twenty-six airport managers (approximately 84 percent) reported to have either informal agreements resulting from minimal dialogue with local emergency responders or rely solely on 911 notifications with no prior interagency agreements established (Figure 2).

\begin{tabular}{|c|l|c|c|}
\hline $\begin{array}{c}\text { Fistent of } \\
\text { Communit } \\
\text { Agreement }\end{array}$ & $0 \%$ & $100 \%$ & $\begin{array}{c}\text { Number of } \\
\text { Airports }\end{array}$ \\
\hline $\begin{array}{c}\text { Formal } \\
\text { Planning }\end{array}$ & $50 \%$ & 5 \\
\hline $\begin{array}{c}\text { Informal- } \\
\text { Dialogue }\end{array}$ & & 14 \\
\hline $\begin{array}{c}\text { No agreement } \\
\text { only } 911 \\
\text { notification }\end{array}$ & Total Respondents: & 18 \\
\hline \multicolumn{2}{|r|}{ Non-Respondents: } & $\mathbf{3 1}$ \\
\hline \multicolumn{2}{r}{} \\
\hline
\end{tabular}

Figure 2. Number of Surveyed Airports with Emergency Response Planning 


\section{The Impact of Increased VLJ Activity}

Many emerging air taxi companies have announced their intention to use very light jets (VLJs) for point-to-point commercial charter services between smaller airports (Viken, 2006). The Federal Aviation Administration predicts that as many as 4,500 very light jets will be flying by 2016 (Robinson and Planzer, 2005). Because of the anticipated growth in VLJ traffic, there is related concern about the availability and quality of safety systems at smaller airports. Clearly, the need for effective emergency response will grow if indeed the amount of commercial jet traffic into smaller airports increases as forecast (Carson, 2004).

Results from Likert-scaled'survey items suggests that there is not much concern among airport managers for improvement of current emergency response planning and preparedness given the prediction of increased VLJ operations at their airports. An emerging theme from responses to open-ended questions was that VLJ operations were viewed as a safer form of transportation (in contrast to other general aviation piston or turboprop operations) although there were concerns with inexperienced pilots and the thoroughness of factory training that they would receive.

The data also suggest that the impact of very light jets had little effect on the airport managers' level of concern regarding improvement of airport personnel emergency training. There was a level of general agreement that improvement is not needed when based solely on increased jet operations. Although some airport managers did support the need for improving airport personnel training, the number of responses in indicating little to no concern was relatively high, at approximately 75 percent.

\section{Conclusion}

This study was designed to assess the current level of emergency preparedness to support VLJ operations at small general aviation airports within the state of Indiana. The findings suggest that few small community airports have sufficient personnel, equipment, financial resources, or training expertise to appropriately conduct frequent fullscale air disaster exercises or respond to actual emergencies. Surveyed airport managers felt that emergency response training was important and needed to improve at their airports. Therefore, it is imperative that local agencies arrange for the acquisition and coordination of firefighting and rescue equipment, particularly emergency equipment that may be missing from airport ARFF inventories. Also, creating or updating airport emergency plans with local community rescue agencies will expedite the airport emergency response efforts.

With regard to the perceived risks of VLJ activity at small general aviation airports in the near future, most airport managers are confident that their airports are prepared to handle this added traffic since they are already servicing business jet aircraft. The prevailing feeling is that VLJs will be safer than many other forms of general aviation transportation currently in use, due to the introduction of new technology that integrates highly automated onboard systems designed to reduce pilot workload and increase situational awareness. With minor upgrades and improvements to amenities and facilities available for current jet operations, small community airports have great potential for enhancing throughput capacity in the National Airspace System (NAS) and become attractive and convenient destinations for business and personal operators of very light jets. The researchers hopes that the findings and recommendations of this study will be useful to airport managers who share concerns about the issues discussed herein.

\section{Recommendations}

As a result of this study, the following recommendations are suggested to improve emergency preparedness for future VLJ activity and as a design template for smaller airports not certified under Part 139. Some recommendations in this section may not be practical to all airports in this study, because of resource limitations. 1. Airport Rapid Response Areas (RRA), should not contain difficult-to-traverse terrain such as high-standing crops, wooded areas, or farm lots; if however, such terrain does exist in the RRA, access roads should be built so that no terrain features prevent rapid ingress by emergency vehicles. Access roads should be at least two lanes wide with special consideration given for access into swamps or mudded areas. Access roads should be capable of sustaining the weight of the largest local emergency vehicle in all weather conditions (FAA, 1995). Although airport authorities are only responsible for emergency response inside the airport boundary, careful planning of airport roads and gates can result in faster response by airport personnel and local emergency responders.

2. Airports should maintain more than one type of fire extinguishing agent - dry chemical, foam, carbon dioxide, and Halon - as readily available on the airport premises. In order to quickly and successfully extinguish an aircraft fire, a variety of suitable extinguishing agents may be required (Flynn, 2007).

3. Airport administrators should invest in rescue equipment and protective gear for airport personnel who are likely to be first responders during aircraft emergency or rescue situations. Typically, airport personnel are the first responders to the scene of an aircraft accident. First responders need to be properly equipped to perform necessary duties. From this study, it was clear that many smaller airports did not have forcible entry tools, medical equipment, or protective gear available. Absence of such equipment will lengthen passenger extrication times, thus lowering survival outcomes. Moreover, without this equipment, responders and airport rescue personnel will be at increased risk for injury to themselves.

4. Community airports should promote ARFF training for 
local firefighters, volunteer community responders, or qualified airport personnel and employees. Most communities in the United States are located within driving distance of a commercial airport. If that airport conducts flight operations with passenger aircraft, in all likelihood, there are firefighting assets on site. It is important to contact nearby airport ARFF departments and investigate potential collaborative resources. Each ARFF firefighter at FAA Part 139-certified airports in the United States is required by federal aviation regulation to receive annual training for every type of passenger aircraft that conducts flight operations at the firefighter's airport. This training should include a live-fire exercise using an aircraft mock-up and surrounding fire. By forming partnerships with ARFF departments, a local fire department, volunteer firefighters, or airport personnel might share in this training experience (Kreckie, 2002).

5. Airport administrators should contact a local chapter of the American Red Cross to find more information on the training programs available (First Aid, Basic Life Support, Advance Life Support) in the community or in adjacent communities. Knowledge of fundamental first aid procedures may be needed to sustain breathing or treat injuries until local EMS arrives at an accident scene. Basic knowledge of medical procedures will also increase chances of survival and could lessen patient recovery time.

6. Airport administrators should create a formal airport emergency plan and encourage formal agreements with local community emergency agencies. An effective emergency reponse plan should include but is not limited to the following (Poirier, 1996):

\author{
*Identification of potential emergency types \\ *Inventory of resources available \\ *Designing a response \\ "Development of "Response Checklists" \\ *Type of command structure \\ *Lines of authority \\ *Contact phone list \\ *Communication resources and requirements \\ *Establishment of command centers \\ *Grid maps \\ *Exercising and testing procedures
}

7. Airport administrators should conduct full-scale live drills (once every three years) and tabletop exercises (annually) with community response agencies. Rescuers must be able to quickly formulate plans to manage emergency response activity. Rescue procedures should follow a plan that has been created and then communicated to the appropriate rescue agency.

\section{Future Studies}

The population sample for this study consisted of general aviation airports within the state of Indiana. In order for results from a study of this kind to be generalized, a national assessment of the airport emergency preparedness and underlying concern with regards to VLJ activity should be done utilizing similar airport selection attributes outlined in this study. In addition to emergency response concerns, there are many emerging issues regarding air taxi services that will operate very light jets. Experience over the next few years should establish the practical niche for these jets, the unexpected operational concerns involved with new technologies, and the safety statistics of VLJ operations. $\rightarrow$ 
Stanley L. Harriman is a doctoral student in the Aviation Technology Department at Purdue University. He currently teaches an aircraft systems course for pilots and flight instructs in the Instrument and Commercial courses at Purdue. Mr. Harriman's research interests include aviation human factors and performance, emergency preparedness, human-system integration, and aviation training needs. He received his Masters degree at Purdue University and currently holds an airframe and powerplant license as well as airplane single and multi-engine, instrument instructor certificates.

Richard O. Fanjoy is an associate professor of Aviation Technology at Purdue University. He currently teaches upper division flight technology and graduate-level courses that address advanced transportation aircraft systems/procedures, high performance aerodynamics, and research design! Dr. Fanjoy's research agenda includes aviation human factors, cognitive models, and advanced flight instrumentation. A retired Air Force Command Pilot with extensive international experience, he has served as a heavy jet aircraft flight instructor, check airman, and aircraft accident investigator.

Donald A. Petrin is an associate professor in the Department of Aviation Technology at Purdue University where he has taught since 1979. His teaching responsibilities have included multi-cultural issues, aviation human factors, crew resource management, subsonic and transonic aerodynamics; transport category automated flight decks, advanced navigation, International Civil Aviation Organization procedures, and advanced collegiate turbine aircraft training. He has authored numerous papers, FAA test preparation guides, and conference presentations. $\mathrm{He}$ is an active member of several international organizations relating to collegiate flight education and serves on the editorial boards of numerous scholarly aviation publications. He has fostered international relationships through his travels to Australia, Canada, China, and Ireland. His research interests have included crew resource management, the cultural impact on aviation knowledge transfer; very light jet training, product support, and airport emergency preparedness. Prof. Petrin has over 34 years of experience as a pilot, with more than 12,000 flight hours primarily in turbine powered aircraft. He holds the Airline Transport Pilot certificate with Diamondjet, Beechjet, and Learjet type ratings and an FAA Gold Seal Certified Flight Instructor, airplane single and multi-engine, instrument airplane 


\section{References}

Boeing Commercial Airplane Group. (1997). Statistical summary of commercial jet aircraft accidents: Worldwide operations, 1959-1996. Seattle, Washington, U.S.: Boeing, Airplane Safety Engineering.

CAAPS. (1999). Surviving the crash. Washington, DC: Coalition for Airport and Airplane Passenger Safety.

Carson, C. (2004). Standards addressing airport fire safety. National Fire Protection Agency Journal, 6(28), 18-20.

Civil Aviation Authority. (2006). Airside safety management CAP 642. London: United Kingdom Commission.

Civil Aviation Authority. (2003). Guidance for developing and auditing a formal safety management system CAP 726. London: United Kingdom Commission.

Comfort, L.K., Ko, K., and Zagarecki, A. (2004). Coordination in rapidly evolving disaster response systems: The role of information. American Behavioral Scientist, 48(3), 295-313.

Espinoza, D. (2006). Implementing an air taxi system. Chile: University of Chile.

European Technical \& Scientific Centre. (1999). Safety in and around airports. Brussels: European Commission.

FAA. (1995). Airport design standards - Advisory circular 150/5335-4. Federal Aviation Administration. Washington DC: U.S. Government Printing Office.

FAA. (1999). Airport emergency plan - Advisory circular 150/5200-31A. Federal Aviation Administration. Washington DC: U.S. Government Printing Office.

FHWA. (1999). Rural road safety: A global challenge. Federal Highway Administration. Washington DC: U.S. Government Printing Office.

Flynn, J. (2007). A guide to aviation firefighting. Madiston, Scotland: UK Fire Service Resources.

Halpin, T. (2003). Down on the farm. Fire Chief, May 1, 2003, Retrieved May 24, 2007, from http://firechief.com/introstitial/?u=http\%3A/firechief.com/mag/firefighting_down_farm.

Hughes, D. (2005). 2025 Squeezeplay. Aviation Week \& Space Technology, 161(19), 44-45.

Hughes, D. (2005). Familiar destinations. Aviation Week \& Space Technology, 163(4), 51-53.

ICAO. (2000). Standards and safety practices. Aerodromes - Aerodrome Design and Operations, Heliports. Annex 14, Section 9.2. Quebec, Canada: International Civil Aviation Organization.

Kiplinger, K. (2006). Short hops ready for takeoff. Kiplinger's Personal Finance, April 18, 2006, Retrieved October 9, 2006, from http:/groundsupportmagazine.com/article/printer.jsp?siteSection=6\&id+1685.

Kreckie, J. (2002). Crash course. Fire Chief, March 1, 2002, Retrieved May 22, 2007, from $\mathrm{http}: / /$ firechief.com/mag/firefighting_crash_course. 
Kuepper, G. J. (2000). Major aviation disasters: Strategies to save lives and control the incident. The Journal of the American Society of Professional Emergency Planners, 10(1), 53-66.

Li, G., Baker, S. (2007). Crash risk in general aviation. Journal of the American Medical Association, 297(14), (Reprinted).

NFPA. (2004). Guide for aircraft accident response. National Fire Protection Association. Sudbury, Massachusetts: Jones and Bartlett Publishers.

NFPA. (2002). Guide for airport/community emergency planning. National Fire Protection Association. Sudbury, Massachusetts: Jones and Bartlett Publishers.

NFPA. (1999). Recommended practice for recurring proficiency training of aircraft rescue and fire-fighting services. National Fire Protection Association. Sudbury, Massachusetts: Jones and Bartlett Publishers.

Osborn, R. (1997). Vertebral fracture after aircraft ejection during operation Desert Storm. Aviation, Space \& Environmental Medicine, 68(4), 337-341.

Poirier, G. M. (1996). A perspective on airport emergency planning for community airports. Hamilton, ON: International Association of Airport Executives Canada.

Rawlingson, C. (2003). Access to quality health services in rural areas - emergency medical services: A literature review. Rural Healthy People 2010. Texas A\&M University System Health Science Center.

Robinson, J. L., \& Planzer, N. (2005). Very light jets: Impacts on NAS operations. Seattle: The Boeing Company.

Spillane, P. D. (2004) Risk perceptions that effect behavior and attitudes in safety programs. Published in the proceedings of the $42^{\text {nd }}$ Annual SAFE Association Symposium. September 27-28. Salt Lake City, Utah.

The Boeing Company. (2005). Current Market Outlook. Seattle: The Boeing Company.

Transport Canada. (2006). Safety management systems assessment guide ( TP14326). Ottawa, ON: Transport Canada.

USDOT. (2004). National average EMS response times for fatal crashes in 2002. United States Department of Transportation. Washington DC: U.S. Government Printing Office.

Viken, J. K. (2006). Nationwide impacts of very light jet traffic in the future next generation air transportation system (NGATS). Hampton, VA: NASA Langley Research Center.

Wall, R. (2005). Hurdles get higher. Aviation week and Space Technology, 163(18), 54.

Wright, J. (2001). Rescue and firefighting research program. Department of Transportation \& Federal Aviation Administration. Washington DC: U.S. Government Printing Office. 